\title{
Calculations of Heating Patterns of Interstitial Antenna for Brain Tumors Hyperthermia Treatment Planning
}

\author{
A. S. Farahat ${ }^{*}$, E. M. El-Dewany", F. M. El-Hefnawi*, Y. M. Kadah ${ }^{* *}$, A. A. Youssef ${ }^{* *}$ \\ "Microwave Engineering Department, Electronics Research Institute, Asmaa@eri.sci.org \\ Department of Biomedical Engineering, Cairo University
}

\begin{abstract}
In this paper a complete thermal analysis has been performed considering an interstitial short dipole antenna implanted inside the human head for brain tumors hyperthermia. For accurate computations, a finite-difference time-domain (FDTD) anatomically based head model is used for analysis. The model composed of seventeen different tissue types with resolution $2 \mathrm{~mm}$. A spherical tumor model with $1.5 \mathrm{~cm}$ diameter is assumed inside the cerebellum with dielectric constant 2-5 times the surrounding normal tissue. The specific absorption rate (SAR) distribution in the human head was determined using FDTD method. The temperature rise around the dipole is calculated. Specifically the bioheat equation was solved also using the FDTD method. The dipole was modeled as a thin wire short dipole with radius $0.3 \mathrm{~mm}$ and half-length $3.5 \mathrm{~mm}$ operating at $400 \mathrm{MHz} .0 .45 \mathrm{~W}$ input power is used, to elevate the tumor temperature to nearly $43^{\circ} \mathrm{C}$. Numerical results showing the validation of the developed computer program are introduced. SAR and Temperature distributions inside the tumor and the surrounding normal tissues are presented.
\end{abstract}

\section{I- Introduction}

Hyperthermia cancer therapy is often used in conjunction with chemotherapy and radiotherapy, since the cytotoxic effect of antitumor drugs is enhanced and the cell killing ability of ionizing radiation is potentiated by hyperthermia [1]. Nevertheless, hyperthermia is still an experimental treatment in the U.S. for late stage patients with advance or recurrent brain tumors, but it has gained some acceptance in Europe and Japan [2]. Clinical and laboratory results indicate that its efficacy depends on the induction of a sufficient temperature rise through the tumor volume. Accordingly, there has been increasing interest in interstitial hyperthermia treatment of brain tumors with control of spatial temperature uniformity within a centimeter [2].

In clinical practice, the quantity of ultimate interest is temperature distribution inside the tumor. However, SAR distribution in tissue provides the driving power responsible for tissue temperature. Moreover, in order to conduct a full investigation of the dynamic temperature variation, one needs to take into account tissue composition, blood perfusion, heat conduction effects of various tissues, and heat generation due to metabolic process. The temperature in this study is computed in two steps. The first step is to compute the SAR distribution in the human head using the finite-difference time-domain (FDTD) method [3], while the other step is to determine the temperature by solving a bioheat equation, which takes into account various heat exchange mechanisms such as heat conduction, blood flow, metabolic heat production, and EM heating also using FDTD method.

In this paper, the human head is modeled as high resolution anatomically based human head model. The details of the model, SAR Computation, and temperature Computations are depicted through the following section. Section III provides the results and discussion, and section IV gives the conclusion of the research. 


\section{II- Methods and Models}

\section{A. Head Model}

The head model used in this study was constructed on the basis of an anatomical magnetic resonance imaging (MRI) model. The MRI images data set contains a high resolution 3D Flash image acquisition at 3T.

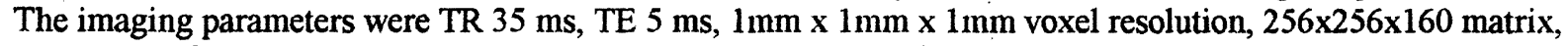
flip angle $40^{\circ}$, scan time $17 \mathrm{~min}$. Each sagittal slice was down-sampled to $128 \times 128$ images with resolution $2 \mathrm{~mm}$ $x 2 \mathrm{~mm}$. A segmentation process was done on each slice to differentiate between the different tissue types in the human head. Such segmentation led to 1310720 cubical cells of tissue with a size of $2 \mathrm{~mm} \times 2 \mathrm{~mm} \times 2 \mathrm{~mm}$. Seventeen types of tissues were involved in this model, Skin, Fat, Bone, Cerebro-Spinal-Fluid (CSF), White mater, Grey matter, Cerebellum, Dura, Cartilage, tongue, Sclera, Vitreous Humor, Eye Lens, Muscles, Blood, Spinal Cord (nerve), and Sinuses (air). Figure (1.a) shows an MRI mid-sagittal vertical cross section and the corresponding section after segmentation. Figure (2) shows an axial cross section through the eye formed after the whole model segmentation. The electric properties of tissues at $400 \mathrm{MHz}$ are given in table I where $\epsilon_{r}$ and $\sigma$ are the relative permittivity and conductivity respectively [4].

Table I

Electric properties of tissues consisted in the human head model

\begin{tabular}{|c|c|c|c|}
\hline & Tissue Type & $\boldsymbol{\epsilon}_{\boldsymbol{r}}$ & $\boldsymbol{\sigma}(\mathbf{S} / \mathbf{m})$ \\
\hline 1 & Skin & 46.7 & 0.688 \\
\hline 2 & Fat & 5.57 & 0.041 \\
\hline 3 & Bone & 13.1 & 0.09 \\
\hline 4 & Dura & 46.6 & 0.827 \\
\hline 5 & CSF & 70.99 & 2.25 \\
\hline 6 & Gray Matter & 57.4 & 0.737 \\
\hline 7 & White Matter & 42.07 & 0.444 \\
\hline 8 & Cerebellum & 55.99 & 1.03 \\
\hline 9 & Cartilage & 45.46 & 0.586 \\
\hline 10 & Muscle & 58.8 & 0.8 \\
\hline 11 & Eye Humor & 69 & 1.529 \\
\hline 12 & Eye Lens & 48.15 & 0.668 \\
\hline 13 & Eye tissue (Sclera) & 57.67 & 1.004 \\
\hline 14 & Blood & 64.18 & 1.349 \\
\hline 15 & Spinal Cord & 35.4 & 0.446 \\
\hline 16 & Tongue & 57.6 & 0.773 \\
\hline 17 & Air & 1 & 0 \\
\hline
\end{tabular}

\section{B. SAR Computation}

To study the interaction of the electromagnetic field from the antenna with the human head, the FDTD method has been employed together with an anatomical heterogeneous model of the human head. The parameters for the FDTD computations were as follows: A space domain enclosing the human head and the implanted antenna had $128 \times 128 \times 80$ cells. Each cell had a size of $\delta=2 \mathrm{~mm}$. The time step $\delta_{t}$ was set to $\delta / \sqrt{3} c$, where $\mathrm{c}$ is the speed of light, to ensure the numerical stability. The time stepping was performed for about four sinusoidal cycles in order to reach a steady state. To absorb the outgoing scattered waves, a uniaxial perfectly matched layer (Geometric graded profile, 8 layers) [5] and [3] are placed at a distance of $1 \mathrm{~cm}$ from the 
head model. The dipole was approached by thin-wire approximation, which includes the effects of a wire with a radius smaller than the FDTD cell dimensions. Once the steady-state condition of the FDTD problem solution is reached, the amplitude of the three components is determined, in the center of each cell, and the SAR distribution is evaluated as [6]

$$
S A R(i, j, k)=\frac{\sigma(i, j, k)\left[\hat{E}_{x}^{2}(i, j, k)+\hat{E}_{y}^{2}(i, j, k)+\hat{E}_{z}^{2}(i, j, k)\right]}{2 \rho(i, j, k)}
$$

where $\sigma(i, j, k)$ and $\rho(i, j, k)$ are the conductivity and density of the tissue filling the $(i, j, k)$ cell. The elevated SAR distribution then used as input term for the solution of the thermal problem.

\section{Temperature-Rise Computation}

The temperature distribution $T=T[x, y, z, t]$ inside the head has been obtained by using the Bioheat equation (BHE) [7]

$$
\nabla \cdot(K . \nabla T)+A+Q_{v}-B\left(T-T_{B}\right)=C \rho \frac{\partial T}{\partial t}\left[\frac{W}{m^{3}}\right]
$$

This equation equals the heat accumulated (or lost) per unit time and per unit volume in a point inside the body (left side), with the temperature increase (or decrease) per unit time multiplied by the thermal capacitance of $1 \mathrm{~m}^{3}$ of tissue (right side). The thermal capacitance is given by the product between tissue specific heat $\left(C\left[\mathrm{~J} /\left(\mathrm{Kg} .{ }^{\circ} \mathrm{C}\right)\right]\right)$ and density $\left(\rho\left[\mathrm{Kg} / \mathrm{m}^{3}\right]\right)$.

In particular, the four terms on the left side of (2) represent different ways through which heat is transferred, produced, or removed inside the tissue, more precisely:

1) heat transfer through internal conduction $\left(K\left[\mathrm{~J} /\left(\mathrm{s} . \mathrm{m} .{ }^{\circ} \mathrm{C}\right)\right]\right)$ is the tissue thermal conductivity);

2) metabolic heat production $\left(A\left[\mathrm{~J} /\left(\mathrm{s} \cdot \mathrm{m}^{3}\right)\right]\right)$;

3) electromagnetic power deposition $\left(Q_{v}\left[\mathrm{~J} /\left(\mathrm{s} . \mathrm{m}^{3}\right)\right]\right)$;

4) heat exchange mechanism due to capillary blood perfusion, proportional to blood flow (through the parameter $\left.B\left[\mathrm{~J} /\left(\mathrm{s} .{ }^{\circ} \mathrm{C} \cdot \mathrm{m}^{3}\right)\right]\right)$ and to the difference between blood and tissue temperature $\left(T_{B}-T\right)$. It must be noted that $T_{B}$ is a function $f$ time.

The aforementioned BHE, in order to be solved, must be completed by an appropriate boundary condition, able to model heat exchange from the skin to the external environment. This boundary condition has been obtained imposing the continuity of the heat flow perpendicular to the surface of the body, and can be expressed as [8]

$$
-K\left(\nabla T \cdot n_{0}\right) S=H\left(T_{S}-T_{A}\right)\left[\frac{W}{m^{2}}\right]
$$

where $S$ is the skin surface and $n_{0}$ is the outward unit vector normal to $S$. Terms on the right hand side represent the two ways in which heat is exchanged with the environment. In particular, the first term models heat losses due to convection and radiation, proportional to the difference between skin temperature $\left(T_{S}\right)$ and external temperature $\left(T_{A}\right)$ through the parameter $\mathrm{H}\left[\mathrm{J} /\left(\mathrm{s} .{ }^{\circ} \mathrm{C} . \mathrm{m}^{2}\right)\right]$.

To obtain an explicit finite-difference formulation of (2) and (3), an approach based on the thermal balance equation is used [7] and is given as.

$$
\begin{gathered}
T_{i, j, k}^{n+1}=T_{i, j, k}^{n}\left[\begin{array}{c}
1-\frac{B \delta_{t}}{C \rho}-N_{\mathrm{int}} \frac{K \delta_{t}}{C \rho \delta^{2}} \\
-N_{e x t} \frac{H \delta_{t}}{C \rho \delta}
\end{array}\right]+N_{e x t} \frac{H \delta_{t} T_{A}}{C \rho \delta}+\frac{\delta_{t}}{C \rho}\left(\begin{array}{c}
S A R_{i, j, k} \rho \\
+A_{i, j, k}+B T_{b}
\end{array}\right) \\
+\frac{K \delta_{t}}{C \rho \delta^{2}}\left[T_{i+1, j, k}^{n}+T_{i-1, j, k}^{n}+T_{i, j+1, k}^{n}+T_{i, j-1, k}^{n}+T_{i+1, j, k}^{n}+T_{i, j, k+1}^{n}+T_{i, j, k-1}^{n}\right]
\end{gathered}
$$


where, $N_{\text {ext }}$ is the number of faces of the $(\mathrm{i}, \mathrm{j}, \mathrm{k})$ cell indirect contact with air, $N_{i n t}$ is the number of faces of the $(\mathrm{i}, \mathrm{j}, \mathrm{k})$ cell indirect contact with the tissue, $\delta_{t}$ and $\delta$ are the discretization step in time and space respectively. The discretization of the bioheat equation follows that of the FDTD lattice used to determine the SAR. The thermal parameters used are shown in table II [8]-[10]. In order to assure stability of the solution, the criteria (courant number),

$$
\frac{K \delta_{t}}{\rho c \delta^{2}} \leq \frac{1}{6}
$$

was invoked by selecting an appropriate value for $\delta_{t}$. For our hyperthermia application, the change of the dielectric constant with temperature is not considered, because of the limited temperature range used in the treatment $\left(37^{\circ} \mathrm{C}-43^{\circ} \mathrm{C}\right)$, and also because of the relative insensitivity of the permittivity of the tissue to temperature variation (typically $2 \%{ }^{\circ} \mathrm{C}$ ). In other words, taking into account the change in the tissue permittivity in the limited temperature range of therapentic interest would only slightly change the calculated SAR distribution pattern.

Due to the unavailability of the dielectric contrast between malignant and normal brain tissue, we consider contrasts in ranging from approximately $5: 1$ down to $2: 1$ in this paper.

Table II

Thermal parameters of the tissues consisted in the human head model, under basal conditions

\begin{tabular}{|c|c|c|c|c|c|c|}
\hline & Tissue Type & $\begin{array}{c}P \\
\left(K g / m^{2}\right)\end{array}$ & $\begin{array}{c}C \\
(J / K g . \\
\left.{ }^{o} \mathrm{C}\right)\end{array}$ & $\begin{array}{c}K \\
\left(J / S \cdot m^{o} C\right)\end{array}$ & $\begin{array}{c}A_{\theta} \\
\left(J / S \cdot m^{3}\right)\end{array}$ & $\begin{array}{c}\boldsymbol{B}_{0} \\
\left(\mathrm{~J} / \mathrm{S}^{\circ}{ }^{\circ} \mathrm{C} \cdot \mathrm{m}^{3}\right)\end{array}$ \\
\hline 1 & Skin & 1010 & 3500 & 0.42 & 1620 & 9100 \\
\hline 2 & Fat & 920 & 2500 & 0.25 & 300 & 1700 \\
\hline 3 & Bone & 1810 & 1300 & 0.40 & 590 & 3300 \\
\hline 4 & Dura & 1010 & 3600 & 0.5 & 7100 & 2700 \\
\hline 5 & $\mathrm{CSF}$ & 1010 & 4200 & 0.62 & 0 & 0 \\
\hline 6 & Gray Matter & 1040 & 3700 & 0.57 & 7100 & 40000 \\
\hline 7 & White Matter & 1040 & 3600 & 0.50 & 7100 & 40000 \\
\hline 8 & Cerebellum & 1050 & 3700 & 0.57 & 7100 & 40000 \\
\hline 9 & Cartilage & 1100 & 3500 & 0.47 & 1600 & 9000 \\
\hline 10 & Muscle & 1040 & 3600 & 0.50 & 480 & 2700 \\
\hline 11 & Eye Humor & 1010 & 4000 & 0.60 & 0 & 0 \\
\hline 12 & Eye Lens & 1050 & 3000 & 0.40 & 0 & 0 \\
\hline 13 & Eye tissue (Sclera) & 1170 & 4200 & 0.58 & 0 & 0 \\
\hline 14 & Blood & 1060 & 3900 & 0.0 & 0 & 0 \\
\hline 15 & Spinal Cord & 1040 & 3500 & 0.46 & 7100 & 40000 \\
\hline 16 & Tongue & 1050 & 3600 & 0.50 & 480 & 2700 \\
\hline 17 & Air & 1.205 & 1000 & 0.03 & 0 & 0 \\
\hline
\end{tabular}

\section{III- Numerical Results and Discussion}

The FDTD numerical code is verified by comparing the near electric field intensity distribution generated by the FDTD code for a half-wave dipole with radius of $0.5 \mathrm{~mm}$ and half-length of $5.3 \mathrm{~cm}$, operating at $400 \mathrm{MHz}$ was located at the center of a lossy homogeneous dielectric sphere whose radius is $9 \mathrm{~cm}$, dielectric constant $\epsilon_{r}=49$ and conductivity $\sigma=0.6 \mathrm{~S} / \mathrm{m}$, and the same data generated using a commercial package XFDTD [11], figure (3). The dipole was assumed to deliver $1 \mathrm{~W}$. In spite of small differences between the two- 
near field distributions due to the finite FDTD cell size $(3.7 \mathrm{~mm})$, the XFDTD simulator generate a remarkable agreement for the implanted antenna.

To verify the generated code for the solution of the bioheat equation, the steady state output of the code was compared to the analytic solution for a $10 \mathrm{~cm} \times 10 \mathrm{~cm} \times 10 \mathrm{~cm}$ cube with the top side $(Z=10 \mathrm{~cm})$ was maintained at a temperature of $600^{\circ} \mathrm{C}$ while all other sides were held at $0^{\circ} \mathrm{C}$, as shown in figure (4). The thermal parameters $\rho, \mathrm{K}, \mathrm{c}$ were all arbitrarily set to 1 for both the numerical and analytical calculations. The steady state temperature of the cube in figure (4.a) is given as [12].

$$
T(x, y, z)=\sum_{\substack{n=1 \\ n \text { odd }}}^{\infty} \sum_{\substack{m=1 \\ m \text { odd }}}^{\infty} \frac{9600}{\pi^{2} m n\left(\sinh \left(\gamma_{m n} C\right)\right)} \sin \left(\alpha_{n} x\right) \cdot \sin \left(\beta_{m} y\right) \sinh \left(\gamma_{m n} z\right)
$$

where

$$
\alpha_{n}=\frac{n \pi}{a} ; \quad \beta_{m}=\frac{m \pi}{b} ; \quad \gamma_{m n}=\sqrt{\alpha_{n}^{2}+\beta_{m}^{2}}
$$

For the numerical calculations, the cube was divided into 1000 cells, with each cell a $1 \mathrm{~cm}$ cube. For all point in the lattice, the difference between the temperature results from the analytic solution and the developed heat transfer program matched with error $<2 \%$.

To verify the transient analysis capabilities of the developed code, the same cube (Fig.4) was used, and the temperature at the center of the cube obtained using the developed heat transfer program were compared to the results of [12]. As can be seen from figure (5), the results of the developed code and [12] agree quite favorably.

As an application for brain tumor hyperthermia, a short dipole with radius $0.3 \mathrm{~mm}$ and half-length $3.5 \mathrm{~mm}$, operating at $400 \mathrm{MHz}$, with $0.25 \mathrm{~W}$ input power is implanted at the center of a spherical tumor of radius $1.5 \mathrm{~cm}$ located in the cerebellum. If immersed in a homogeneous medium of tumor, the short dipole is expected to dissipate power on a very small area around it. As shown in figure (6), the electric field distribution as a function of the radial distance between the dipole and observation point along the normal direction to the axis of the dipole has a fast decaying rate for different electric properties of tumor. The tumor dielectric properties are assumed 2-5 times that of the surrounding normal tissue. The SAR distribution in a plane containing the antenna is shown is figure (7), for a tumor with dielectric constant 2 times that of the normal tissues. Figure (8) gives the corresponding temperature distribution. As can be seen from figure (8), the temperature is distributed on a very small area around the dipole. This is a required property for hyperthermia applications. A contour plot of the temperature distribution for tumor properties three and five times that of the normal tissues is shown in figure (9). It can be seen that the temperature still distributes on a small area for large dielectric contrast $5: 1$. The steady state temperature was obtained after approximately five minutes of heating.

\section{IV-Conclusion}

A 3-D computer code for calculating the SAR and heat pattern of microwave interstitial antennas was developed and a sample results for brain tumors hyperthermia were presented. A unique feature of the developed code is related to the realistic calculations of the SAR and heat distribution due to a short dipole using the finite-difference time-domain (FDTD) method. It is shown that the SAR distribution and consequently the heat patterns are distributed on small area around the dipole. In all the developed code with its FDTD SAR calculation and the temperature calculation capabilities may play an important role in clinic planning of heat treatments using interstitial antennas. Specific tumor geometries may be modeled, other types of antennas also can be used for clinic heat application planning. 


\section{REFERENCES}

[1] P. Narayan, I. Crocker, E. Elder, and J. Olson, "Safety and efficacy of concurrent interstitial radiation and hyperthermia in the treatment of progressive malignant brain tumors", Oncol. Reports 11: 97-103, 2004

[2] J. C. Lin, S. Hirai, C. L. Chiang, W. L. Hsu, J. L. Su, and Y. J. Wang, "Computer simulation and experimental studies of SAR distributions of interstitial arrays of sleeved-slot microwave antennas for hyperthermia treatment of brain tumors," IEEE Trans. Microwave Theory Tech., vol. 48 , No. 11, pp. 21912198, Nov 2000.

[3] Taflove, S. C. Hagness, Computational Electrodynamics: the finite difference time domain method ( $2^{\text {nd }}$ edition), Artech House, Boston, 2000

[4] http://www.fcc.gov/fcc-bin/dielec.sh

[5] J. P. Berenger, "A perfectly matched layer for the absorption of electromagnetic waves," J. Comput. Phys., vol. 114, pp. 185-200, 1994.

[6] Caputa, M. Okoniewski, and M. stuckly, "An algorithm for computations of the power deposition in human tissue", IEEE Antennas and Propagation Magazine, Vol. 41, No. 4, August 1999

[7] P. Bernardi, M. Cavagnaro, S.Pissa, and E. Piuzzi,"Specific absorption rate and temperature elevation in a subject exposed in the far field of radio-frequency sources operating in the 10-900 $\mathrm{MHz}$ range", IEEE Trans. Biomedical Eng., vol. 50, No. 3, March 2003

[8] R. G. Gordan, R. B. Roeomer, and S. M. Horvath, "A mathematical model of the human temperature regulatory system - transient cold exposure response", IEEE Trans. Biomedical Eng., vol. BME-23, No. 6, November 1976

[9] J. Kim and Y. R. Samii, "Implanted antennas inside a human body: simulations, designs and characterizations," IEEE Trans. Microwave Theory Tech., vol. 52, No. 8, pp. 1934-1943, Aug 2004.

[10] P. Bernardi, M. Cavagnaro, S.Pissa, and E. Piuzzi,"Specific absorption rate and temperature increases in the head of a cellular phone user," IEEE Trans. Microwave Theory Tech., vol. 48, No. 7, July 2000

[11] http://www.remcom.com/xfdtd6

[12] P. C. Cherry, and M. F. Iskander, "Calculations of heating patterns of an array of microwave interstitial antennas”, IEEE Trans. Biomedical Eng., vol. 40, No. 8, March 1993 
The $23^{\text {rd }}$ National Radio Science Conference (NRSC 2006)

March 14-16, 2006

Faculty of Electronic Engineering, Menoufiya University, Egypt.

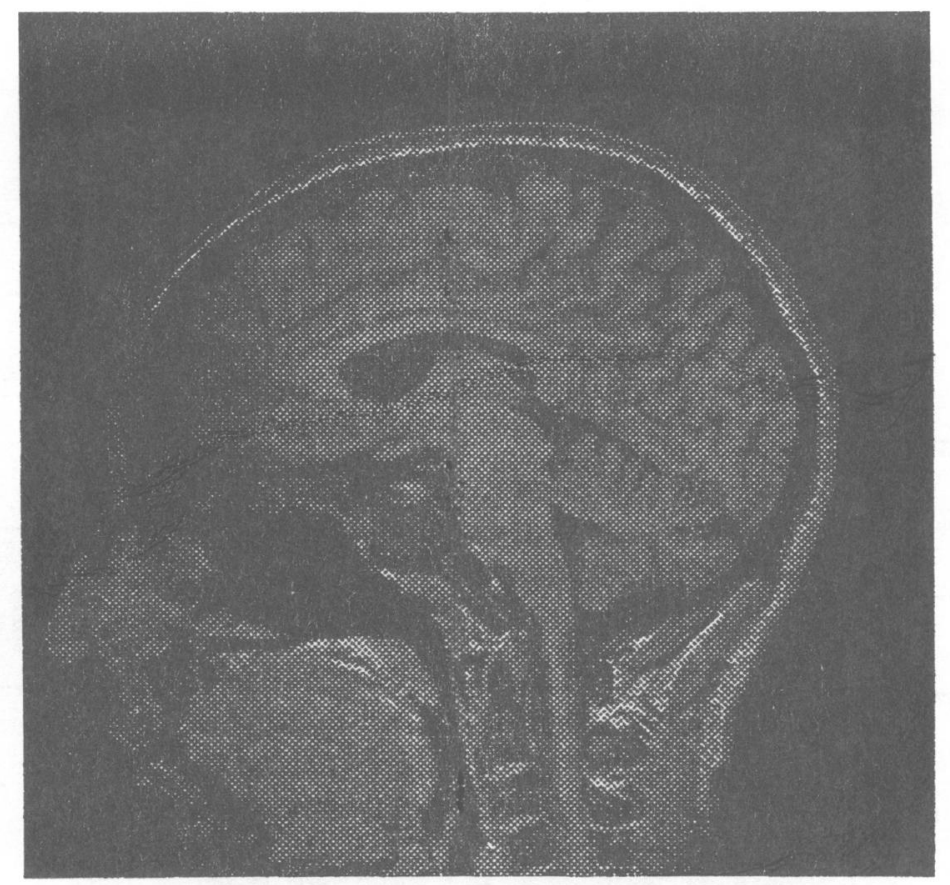

(a)

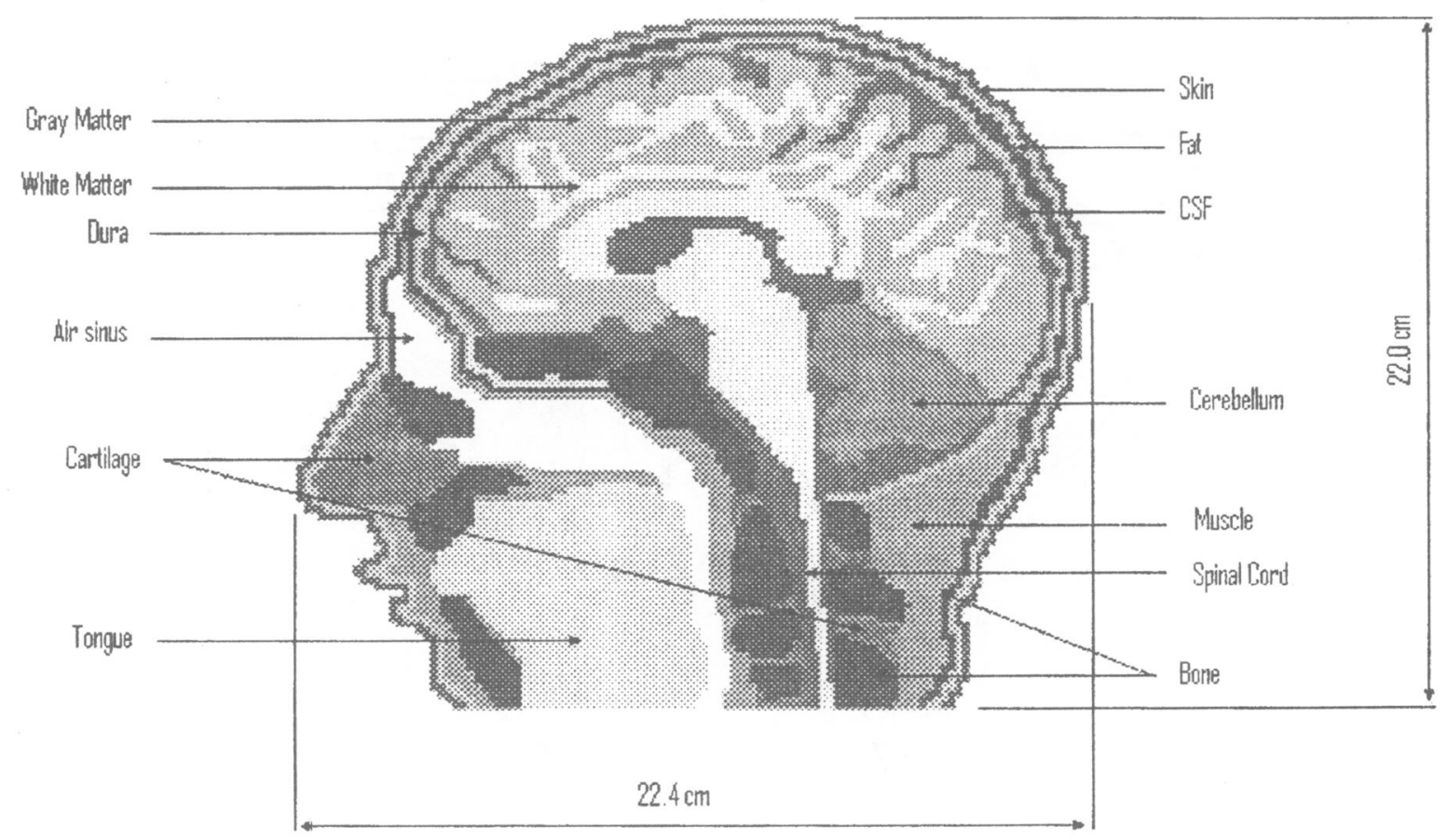

(b)

Fig.1 Mid-Sagittal Cross-section through the model a) MRI B) FDTD 
The $23^{\text {rd }}$ National Radio Science Conference (NRSC 2006)

March 14-16, 2006

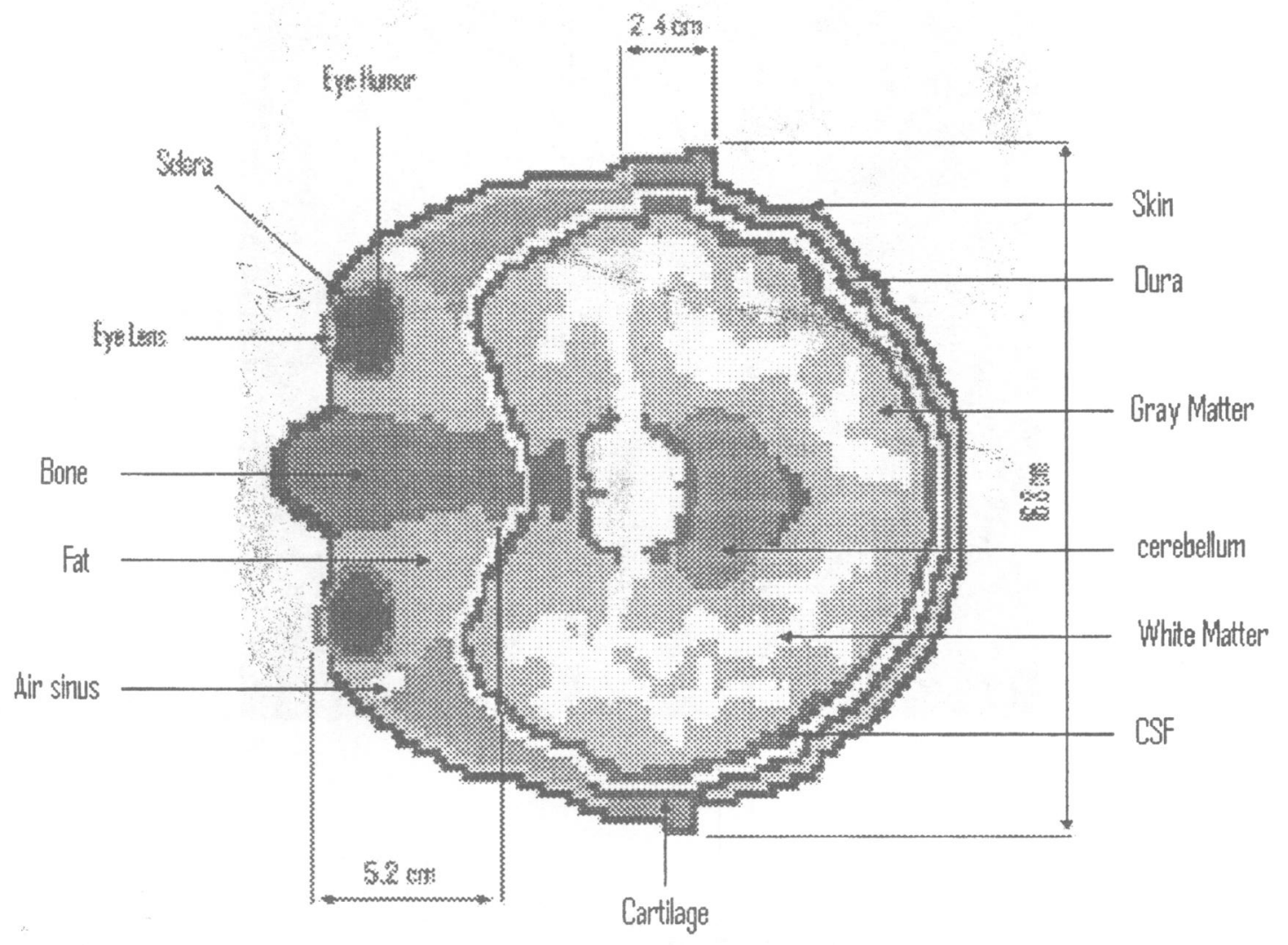

Fig. 2 Axial Cross-section through the FDTD model

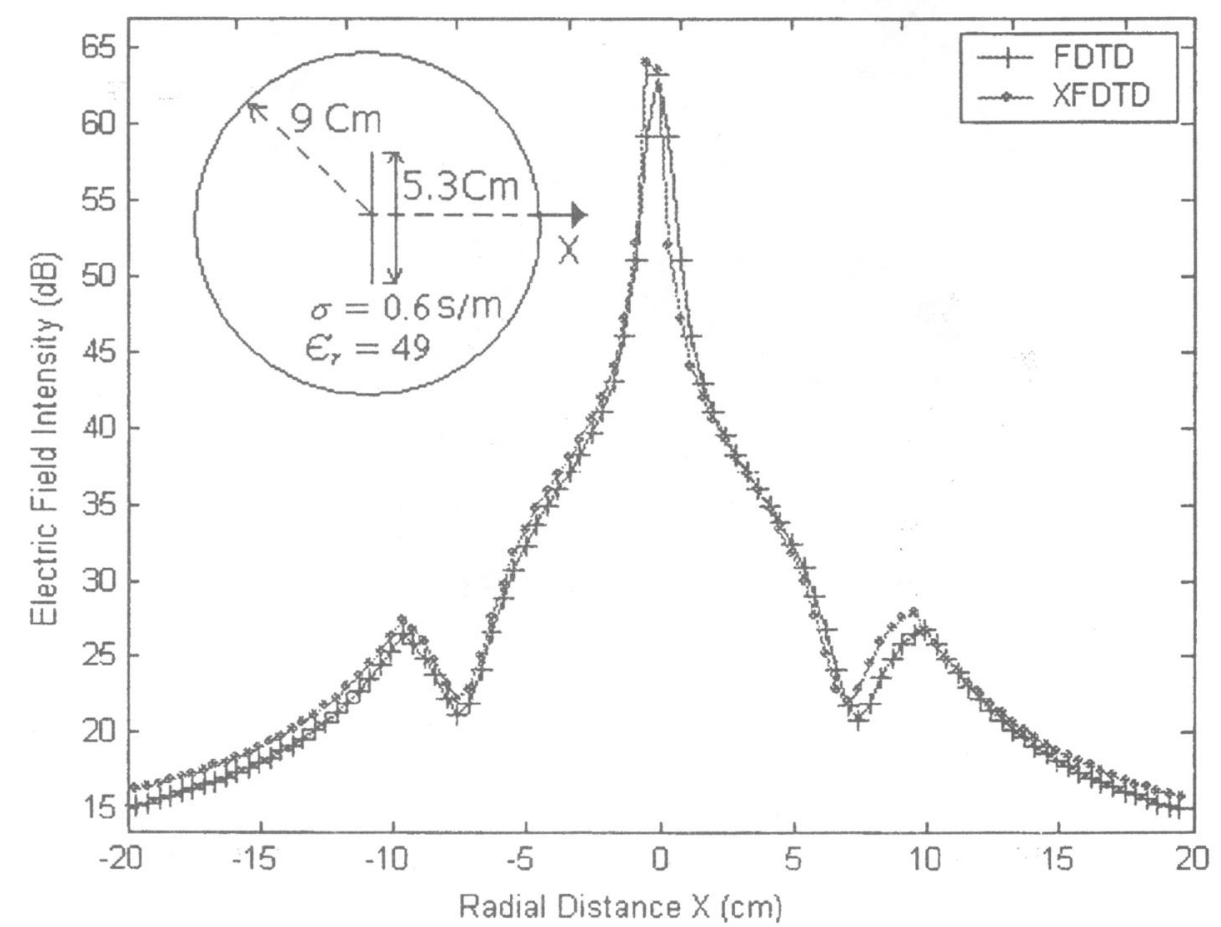

Fig.3 Accuracy evaluation of the FDTD code in comparison with the electric field intensity obtained by XFDTD package 


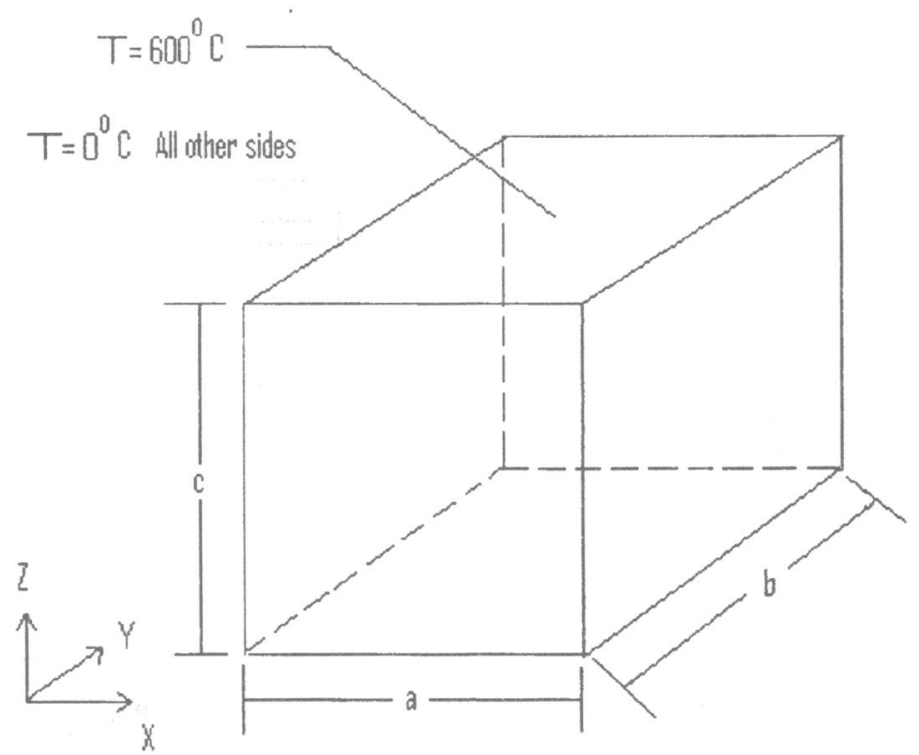

Fig. 4 Geometry of the cubical model used in validating the temperature distribution code. $a=b=c=10 \mathrm{~cm}$. the top side $Z=10 \mathrm{~cm}$ was maintained at a temperature $\mathrm{T}=600^{\circ} \mathrm{C}$

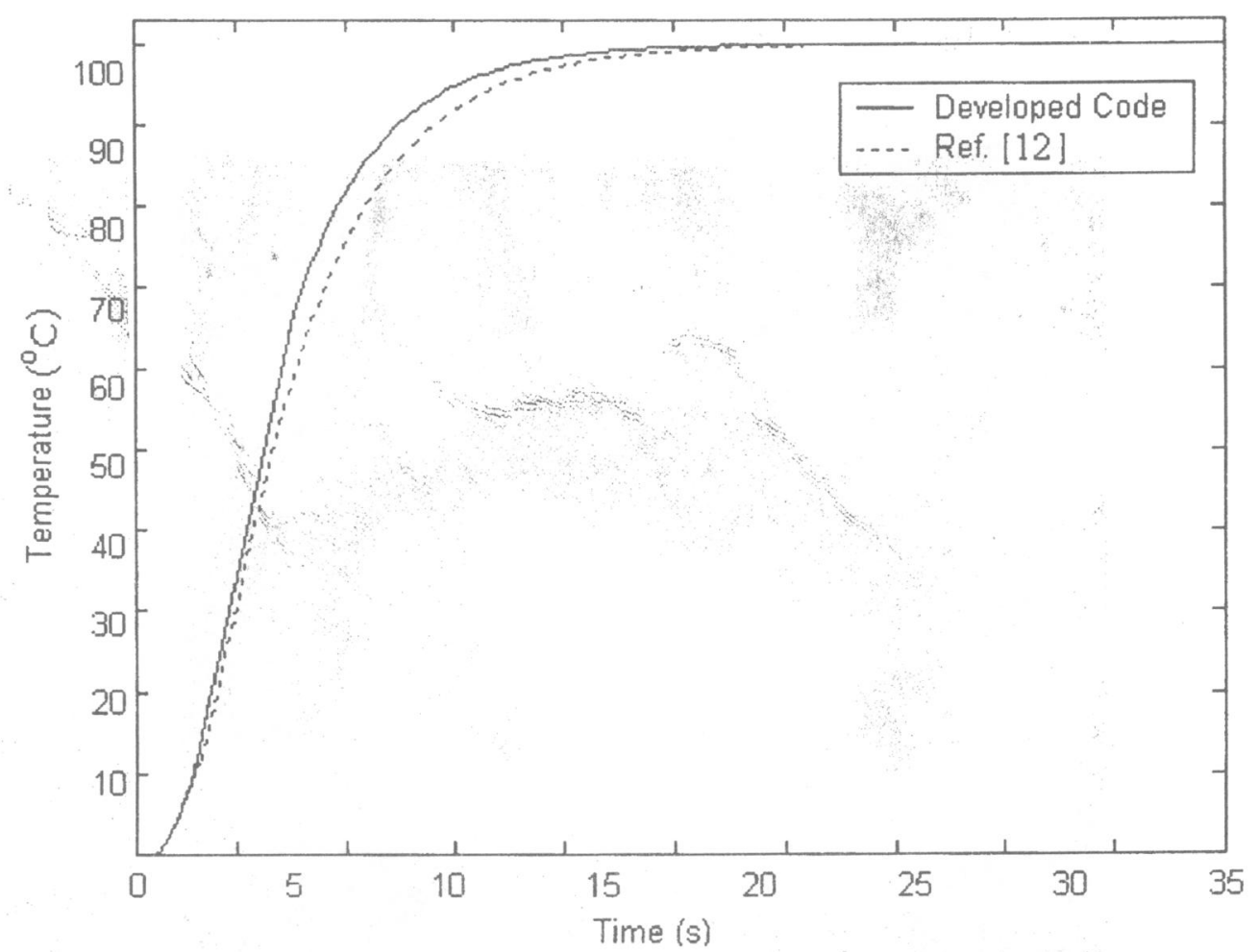

Fig.5 Comparison between the transient variations of the temperature at the center of the cubical model shown in Figure (4) as obtained from the FDTD code and [12] 
The $23^{\text {rd }}$ National Radio Science Conference (NRSC 2006)

March 14-16, 2006

Faculty of Electronic Engineering, Menoufiya University, Egypt.

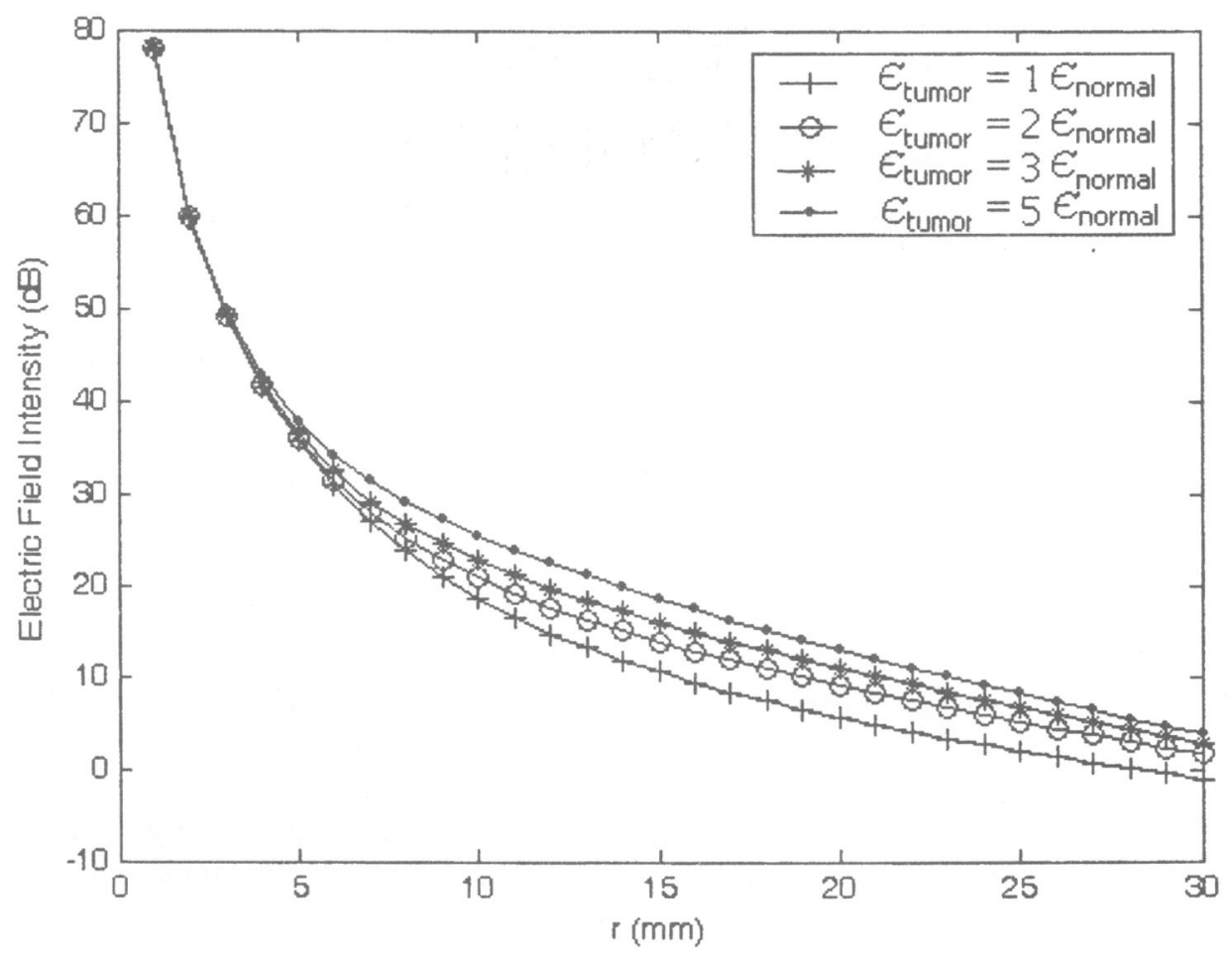

Fig.6. Electric field intensity extension for different tumor properties
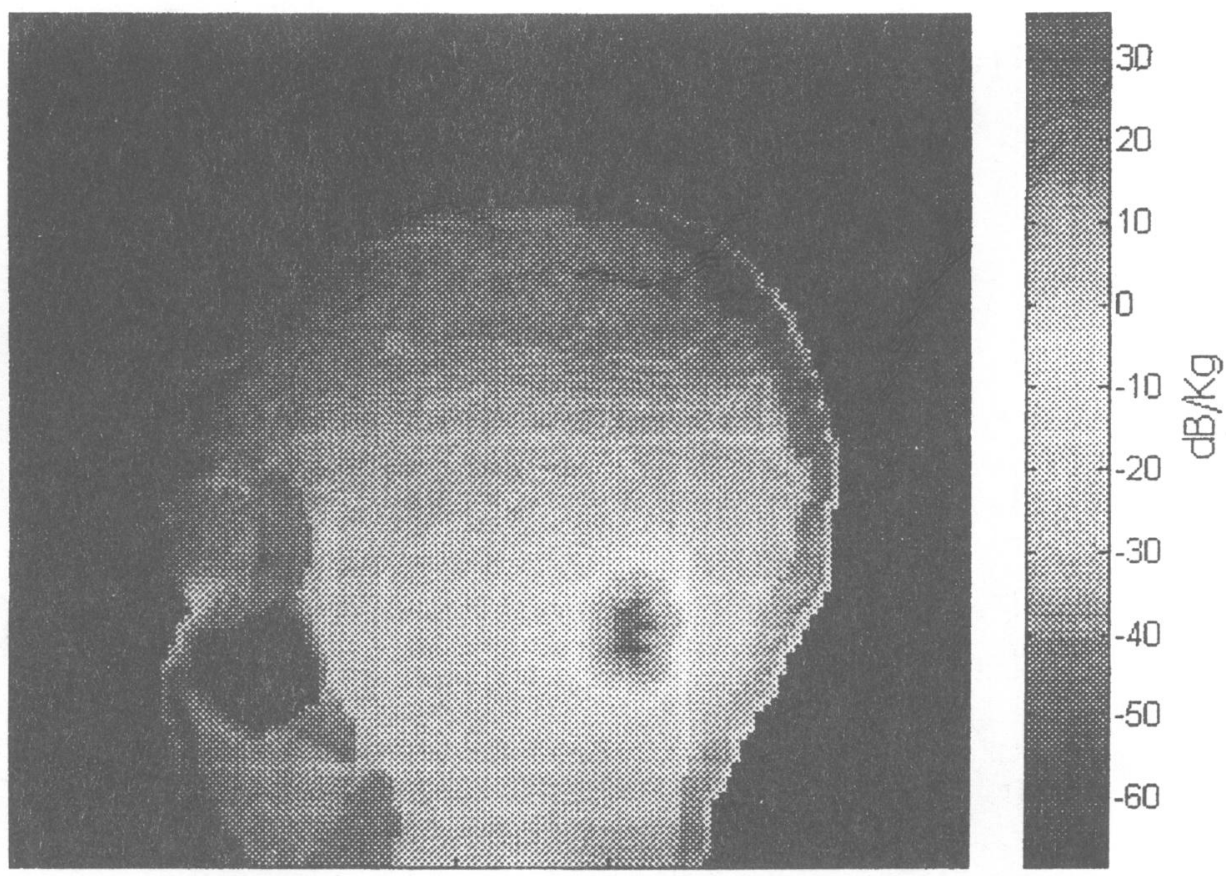

Fig.7 SAR distribution in a sagittal cross-section containing the antenna passing through the center of a tumor of radius $1.5 \mathrm{~cm}$ with $\epsilon_{r, \text { tumor }}=2 \epsilon_{\mathrm{r}, \text { Normal }}$ 
The $23^{\mathrm{rd}}$ National Radio Science Conference (NRSC 2006)

March 14-16, 2006

Faculty of Electronic Engineering, Menoufiya University, Egypt.
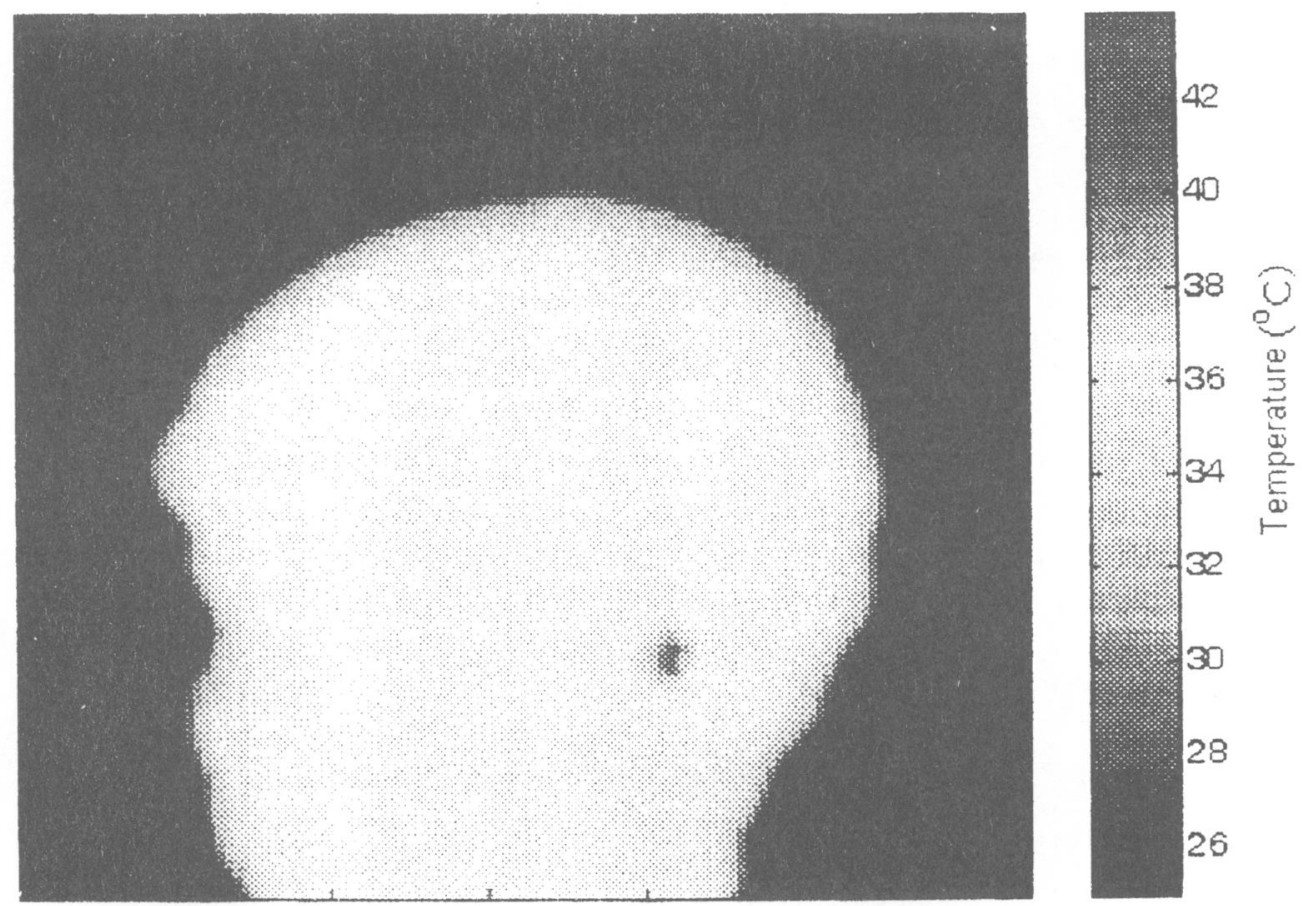

Fig.8 Temperature distribution resulted from the SAR of fig. (7).

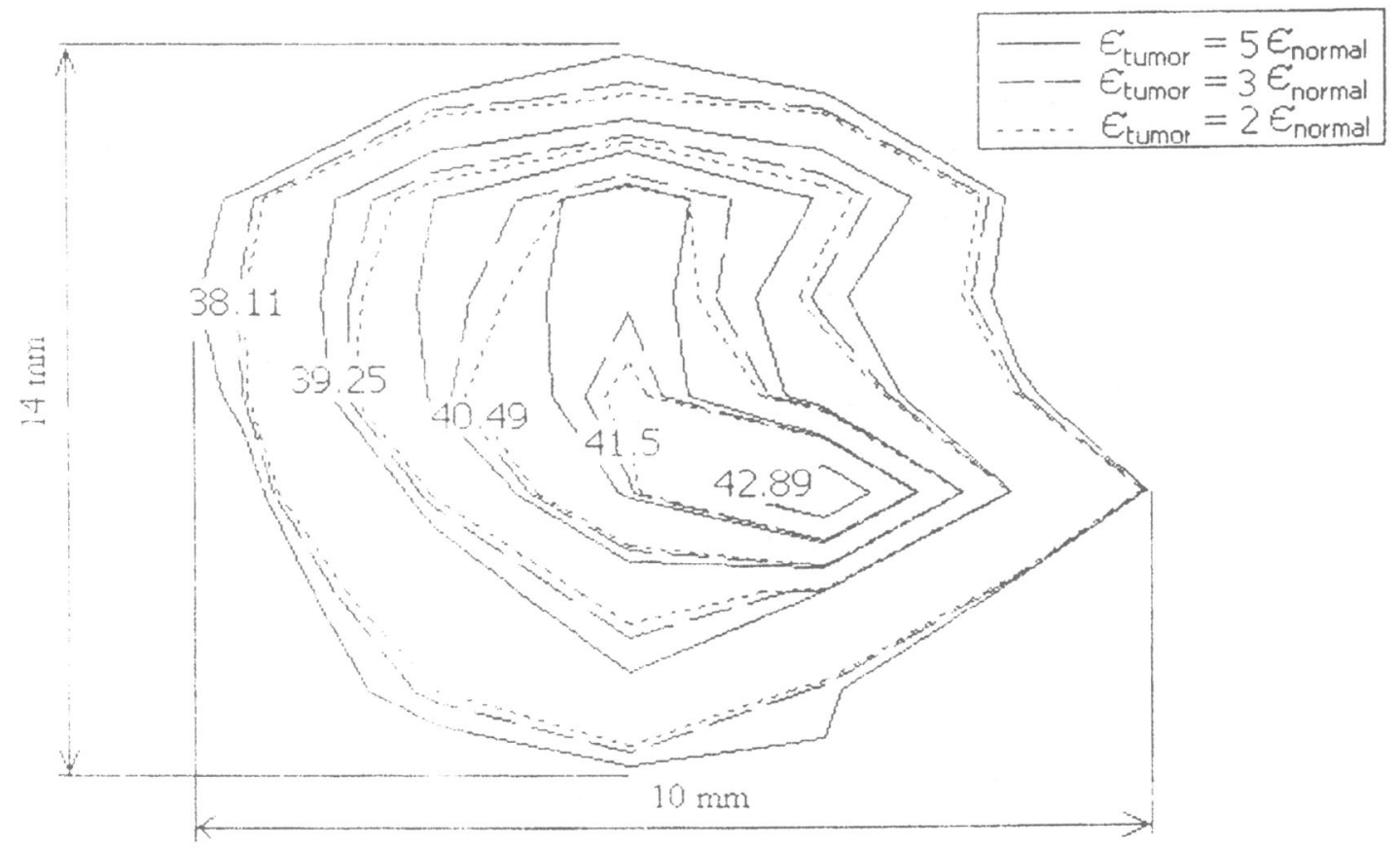

Fig. 9 Contour plots of the temperature distribution in the small area around the antenna resulted from Implanting the antenna in three tumors with dielectric constants 2.3 . and 5 times the normal tissue of the cerebcllum. 